\title{
Movement disorder and sensorimotor abnormalities in schizophrenia and other psychoses - European consensus on assessment and perspectives
}

Citation for published version (APA):

Walther, S., van Harten, P. N., Waddington, J. L., Cuesta, M. J., Peralta, V., Dupin, L., Foucher, J. R., Sambataro, F., Morrens, M., Kubera, K. M., Pieters, L. E., Stegmayer, K., Strik, W., Wolf, R. C., \& Hirjak, D. (2020). Movement disorder and sensorimotor abnormalities in schizophrenia and other psychoses European consensus on assessment and perspectives. European Neuropsychopharmacology, 38, 25-39. https://doi.org/10.1016/j.euroneuro.2020.07.003

Document status and date:

Published: 01/09/2020

DOI:

10.1016/j.euroneuro.2020.07.003

Document Version:

Publisher's PDF, also known as Version of record

Document license:

Taverne

Please check the document version of this publication:

- A submitted manuscript is the version of the article upon submission and before peer-review. There can be important differences between the submitted version and the official published version of record.

People interested in the research are advised to contact the author for the final version of the publication, or visit the DOI to the publisher's website.

- The final author version and the galley proof are versions of the publication after peer review.

- The final published version features the final layout of the paper including the volume, issue and page numbers.

Link to publication

\footnotetext{
General rights rights.

- You may freely distribute the URL identifying the publication in the public portal. please follow below link for the End User Agreement:

www.umlib.nl/taverne-license

Take down policy

If you believe that this document breaches copyright please contact us at:

repository@maastrichtuniversity.nl

providing details and we will investigate your claim.
}

Copyright and moral rights for the publications made accessible in the public portal are retained by the authors and/or other copyright owners and it is a condition of accessing publications that users recognise and abide by the legal requirements associated with these

- Users may download and print one copy of any publication from the public portal for the purpose of private study or research.

- You may not further distribute the material or use it for any profit-making activity or commercial gain

If the publication is distributed under the terms of Article $25 \mathrm{fa}$ of the Dutch Copyright Act, indicated by the "Taverne" license above, 


\title{
Movement disorder and sensorimotor abnormalities in schizophrenia and other psychoses - European consensus on assessment and perspectives
}

\author{
Sebastian Walther ${ }^{\mathrm{a}}$, Peter N. van Harten ${ }^{\mathrm{b}}$, \\ John L. Waddington ${ }^{c}$, Manuel J. Cuesta ${ }^{d}$, Victor Peralta ${ }^{e}$, \\ Lucile Dupin $^{f}$, Jack R. Foucherg,h, Fabio Sambataro ${ }^{i, j}$, \\ Manuel Morrens ${ }^{k, l}$, Katharina M. Kuberam, Lydia E. Pieters ${ }^{b}$, \\ Katharina Stegmayer ${ }^{\mathrm{a}}$, Werner Strik ${ }^{\mathrm{a}}$, R. Christian Wolf ${ }^{\mathrm{m}}$, \\ Dusan Hirjak ${ }^{\mathrm{n}, *}$
}

\footnotetext{
a Translational Research Center, University Hospital of Psychiatry, University of Bern, Switzerland ${ }^{b}$ Psychiatric Center GGz Centraal, Amersfoort, The Netherlands; Department of Psychiatry, School for Mental Health and Neuroscience, Maastricht University Medical Center, Maastricht, the Netherlands 'School of Pharmacy and Biomolecular Sciences, Royal College of Surgeons in Ireland, Dublin, Ireland dDepartment of Psychiatry, Complejo Hospitalario de Navarra, Spain. Instituto de Investigación Sanitaria de Navarra (IdisNa), Spain e Mental Health Department, Servicio Navarro de Salud, Pamplona, Spain, Navarra Institute for Health Research, IdiSNA, Pamplona, Spain fInstitut de Psychiatrie et Neurosciences de Paris, INSERM U1266, Université de Paris, Paris, France gICube - CNRS UMR 7357, Neurophysiology, FMTS, University of Strasbourg, Strasbourg, France ${ }^{\mathrm{h}}$ CEMNIS - Noninvasive Neuromodulation Center, University Hospital Strasbourg, Strasbourg, France 'Department of Neuroscience (DNS), University of Padova, Padova, Italy

${ }^{j}$ Padova Neuroscience Center, University of Padova, Padua, Italy

${ }^{k}$ Department of Psychiatry, University Psychiatric Center Duffel, Duffel, Belgium

'Department of Psychiatry, Collaborative Antwerp Psychiatric Research Institute (CAPRI), Faculty of Medicine and Health Sciences, University of Antwerp, Antwerp, Belgium

m Center for Psychosocial Medicine, Department of General Psychiatry, Heidelberg University, Heidelberg, Germany "Department of Psychiatry and Psychotherapy, Central Institute of Mental Health, Medical Faculty Mannheim, Heidelberg University, Mannheim, Germany
}

Received 22 April 2020; received in revised form 6 June 2020; accepted 6 July 2020

\footnotetext{
* Corresponding author at: Department of Psychiatry and Psychotherapy, Central Institute of Mental Health, D-68159 Mannheim, Germany E-mail address: dusan.hirjak@zi-mannheim.de (D. Hirjak).
} 


\section{KEYWORDS}

Movement disorders;

Sensorimotor

abnormalities;

Schizophrenia;

Psychosis;

Consensus;

Psychomotor

\begin{abstract}
Over the last three decades, movement disorder as well as sensorimotor and psychomotor functioning in schizophrenia (SZ) and other psychoses has gained greater scientific and clinical relevance as an intrinsic component of the disease process of psychotic illness; this extends to early psychosis prediction, early detection of motor side effects of antipsychotic medication, clinical outcome monitoring, treatment of psychomotor syndromes (e.g. catatonia), and identification of new targets for non-invasive brain stimulation. In 2017, a systematic cooperation between working groups interested in movement disorder and sensorimotor/psychomotor functioning in psychoses was initiated across European universities. As a first step, the members of this group would like to introduce and define the theoretical aspects of the sensorimotor domain in SZ and other psychoses. This consensus paper is based on a synthesis of scientific evidence, good clinical practice and expert opinions that were discussed during recent conferences hosted by national and international psychiatric associations. While reviewing and discussing the recent theoretical and experimental work on neural mechanisms and clinical implications of sensorimotor behavior, we here seek to define the key principles and elements of research on movement disorder and sensorimotor/psychomotor functioning in psychotic illness. Finally, the members of this European group anticipate that this consensus paper will stimulate further multimodal and prospective studies on hypo- and hyperkinetic movement disorders and sensorimotor/psychomotor functioning in SZ and other psychotic disorders.
\end{abstract}

(C) 2020 Elsevier B.V. and ECNP. All rights reserved.

\section{Introduction}

Over several decades, research interest in hypokinetic, hyperkinetic, sensorimotor and psychomotor abnormalities in schizophrenia (SZ) and other psychoses has grown steadily. This journey has traversed the pre-antipsychotic era, through the initial post-antipsychotic era during which such abnormalities were primarily interpreted as adverse effects of antipsychotics, to re-discovery that such abnormalities are evident in the antipsychotic-naïve state and reflect sensorimotor and psychomotor deficits intrinsic to the disease process of psychosis that can be modulated by antipsychotics (Cuesta and Peralta, 2018; Hirjak et al., 2020, Hirjak et al., 2020a; Mittal and Walther, 2019; Stevens, 1974; Walther et al., 2019b; Walther and Strik, 2012). Numerous neuroscientists across Europe and beyond have devoted themselves to various aspects of sensorimotor and psychomotor behavior in both antipsychotic-naive and medicated patients with SZ and other psychoses (Cuesta et al., 2018a,b; Hirjak et al., 2015b; Mittal et al., 2017; Northoff, 2016a,b; Northoff et al., 1999b, 2004; Peralta et al., 2010b; Peralta and Cuesta, 2017; Walther et al., 2019b; Walther and Mittal, 2017, 2019c; Walther and Strik, 2012; Whitty et al., 2009).

Although this initiative calls nowadays for a greater understanding of domain- and sensorimotor-based research and classification of SZ and other psychoses, this perspective was not always self-evident. For example, in the 1980s authors proposing hypo- and hyperkinetic motor abnormalities to be integral to the disease process of SZ (Waddington and Crow, 1988; Waddington and O'Tuathaigh, 2018; Whitty et al., 2009) were considered iconoclastic or even heretical, due to strong belief in the psychiatric community that movement disorder in SZ, such as abnormal involuntary movements (AIM, dyskinesia), were essentially a side effect of antipsychotic medication. Over subsequent years it took much effort to achieve recognition of AIM as an intrinsic component of psychotic illness and a manifestation of subtle dysfunction in cortical-basal ganglia-cortical circuitry with implications for psychopathological symptoms, length of hospitalization, treatment resistance and cognition (Chouinard et al., 1979; Pappa and Dazzan, 2009; Yarden and Discipio, 1971). Importantly, the majority of SZ patients appear inherently vulnerable to the emergence of AIM (Quinn et al., 2001) in association with frontal lobe dysfunction in terms of cognitive (i.e. executive) impairment (Waddington, 1995).

These and other relationships can now be examined in more detail using the latest genetic, neuroimaging and behavioral methods. Among the most relevant areas of research on sensorimotor abnormalities are: (1) sensorimotor development in children and adolescents (Filatova et al., 2017, 2018), (2) sensorimotor abnormalities as vulnerability markers in individuals with psychosis risk syndrome (Bernard and Mittal, 2014; Kent et al., 2019; Kindler et al., 2019; Mittal et al., 2014), (3) sensorimotor signs and symptoms as predictors of the clinical course in patients with first-episode SZ (Cuesta et al., 2018a, 2014), (4) neuronal correlates of sensorimotor and psychomotor dysfunction in SZ spectrum disorders (Hirjak et al., 2019; Martino et al., 2020, 2018; Northoff et al., 2004; Walther et al., 2017a,b), (5) impaired hand gesture performance in SZ (Dutschke et al., 2018; Viher et al., 2018; Walther et al., 2019a, 2016; Walther and Mittal, 2016; Walther et al., 2015b), (6) assessment of movement abnormalities with objective instruments (Mentzel et al., 2016b; van Harten et al., 2017; Willems et al., 2016), (7) motor systems as a novel target for transcranial magnetic stimulation (TMS) (Mittal and Walther, 2019) and, as a cross-cutting objective, (8) contrasting their different empirically defined models, e.g. dimensional vs categorical, on various biological measurements, respectively. 
This trend has led to an increasing number of scientific publications, which have not only highlighted the clinical need for early detection of extrapyramidal motor symptoms (EPMS) or tardive dyskinesia, but have also provided numerous neurobiological findings and clinically relevant applications based on sensorimotor system pathology in patients with SZ spectrum disorders (Hirjak et al., 2020). Fortunately, the NIHM Research Domain Criteria (RDoC) initiative has recently introduced a sixth domain called "sensorimotor domain" devoted to sensorimotor system deficits and behavioral abnormalities (Sanislow et al., 2019).

In recognition of this development in the sensorimotor domain and as a result of fruitful scientific discourse during previous conferences held by national and international psychiatric associations in Europe, a new systematic collaboration of experts in the field of movement disorder as well as sensorimotor and psychomotor functioning in SZ and other psychoses called European collaboration on movement and sensorimotor/psychomotor functioning in SZ and other psychoses (ECSP) was established. The members of ECSP will deliver and discuss experimental work (including methods and results) on neural mechanisms and putative clinical implications of movement disorder as well as sensorimotor and psychomotor functioning in SZ and other psychoses.

For this purpose, this consensus paper describes the fundamental principles and key elements of movement disorder as well as sensorimotor and psychomotor functioning in SZ and other psychoses. This paper provides a common conceptual framework on standards for clinical assessment and research on movement as well as sensorimotor and psychomotor functioning. Finally, this paper also focuses on the relevance of the human sensorimotor system for the development of modern and personalized non-invasive stimulation techniques. Each perspective consists of different topics that illustrate different sensorimotor phenomena or research approaches to sensorimotor and psychomotor functioning, followed by a brief discussion of the literature and recommendations.

\section{Methods}

The ECSP was formed during the last two European Conferences on Schizophrenia Research (2017 and 2019), which were held in Berlin, Germany. In fact, a section on motor behavior was established within the European Scientific Association on Schizophrenia and other Psychoses (ESAS). This manuscript summarizes the fruitful discussions on clinical and scientific concepts of the sensorimotor domain within joint symposia during previous scientific conferences in Europe. The main goal of ECSP is to foster collaboration and dissemination of knowledge among experts in sensorimotor and psychomotor functioning across Europe and beyond. The ECSP is highly multidisciplinary, including basic researchers, psychiatrists, psychologists, and neuroscientists. The results section of the consensus paper is structured according to the RDoC matrix, reflects the current state of research and should provide important ideas and guidance (incl. multidisciplinary collaboration and standardized core assessments) for future studies into the sensorimotor domain in SZ and other psychoses. Individual sections were written by individual authors or groups of authors. The shared research goals presented here have been discussed with all co-authors of this article and represent a consensus that should be taken into account in future studies examining movement as well as sensorimotor and psychomotor functioning in SZ and other psychoses (Fig. 1).

\section{Results}

\subsection{Molecules, cells and animal models}

The long and controversial road to (re)identifying movement disorder as intrinsic to psychosis and investigating its pathobiology in terms of systems dysfunction (Whitty et al., 2009) has been due in considerable part to limitations in studying antipsychotic-naïve patients across the natural trajectory of psychotic illness. Understanding these processes has been facilitated by the introduction of animal models that allow both hypokinetic and hyperkinetic movement disorders and their neural mechanisms to be studied in the absence of what would usually be ubiquitous treatment with antipsychotic drugs in clinical samples (Waddington, 1990; Waddington and O'Tuathaigh, 2018). For brevity, this section focuses on hyperkinetic phenomena, more specifically orofacial dyskinesia as an exemplar, with related arguments applying to hypokinetic/parkinsonian phenomena (Waddington, 2020; Waddington and O'Tuathaigh, 2018).

Studies have shown that orofacial dyskinesia induced by long-term treatment with antipsychotic drugs in young rats is, in fact, the premature precipitation and exacerbation by such treatment of a baseline level of spontaneous and innate orofacial motor patterns that would otherwise emerge to excess as a consequence of systems dysfunction associated with processes of maturation-ageing (Waddington, 1990; Waddington and O'Tuathaigh, 2018). Subsequent work has exploited the incisiveness of genetically modified mice to disrupt specific neuronal processes. These resolve the specific roles in individual topographies of spontaneous and DA agonist-induced orofacial movement for: $D_{1-5}$ DA receptor subtypes; the DA transducer DARPP. 32; the GABA synthesizing enzyme GAD65; the GABA recep- $^{-}$ tor regulator PRIP-1/2; and GluN2A, B and D glutamate receptor subtypes (Waddington et al., 2011; Waddington and O'Tuathaigh, 2018). The above studies, using constitutive mutant mice in which the target is disrupted throughout the brain, have identified a prominent role for the D1 receptor in regulating the topography of spontaneous orofacial dyskinesia. They have been followed by studies to parcellate the regionality of these topographical motor effects using conditional mutants that selectively disrupt the target in the forebrain (i.e. including cortex and striatum) vs. medium spiny neurons in the striatum vs. cortical pyramidal neurons (Waddington and O'Tuathaigh, 2018). Such studies are given clinical relevance by the finding that mutant mice with disruption to the SZ risk gene neuregulin-1 show a topographically specific increase in spontaneous orofacial dyskinesia (Waddington and O'Tuathaigh, 2018).

In synthesis, these studies on spontaneous, innate rodent motor patterns substantiate and elaborate concepts deriving from clinical studies. They point to corticalsubcortical network (dys)function involving cortical-basal ganglia-thalamocortical/cerebellar systems similar to those implicated in the pathobiology of SZ (Waddington and O'Tuathaigh, 2018). Furthermore, they are fully congruent with the recent extension of NIMH RDoC to include a sensorimotor systems domain, more specifically its constructs of 'motor actions' and 'innate motor patterns' (Sanislow et al., 2019). 


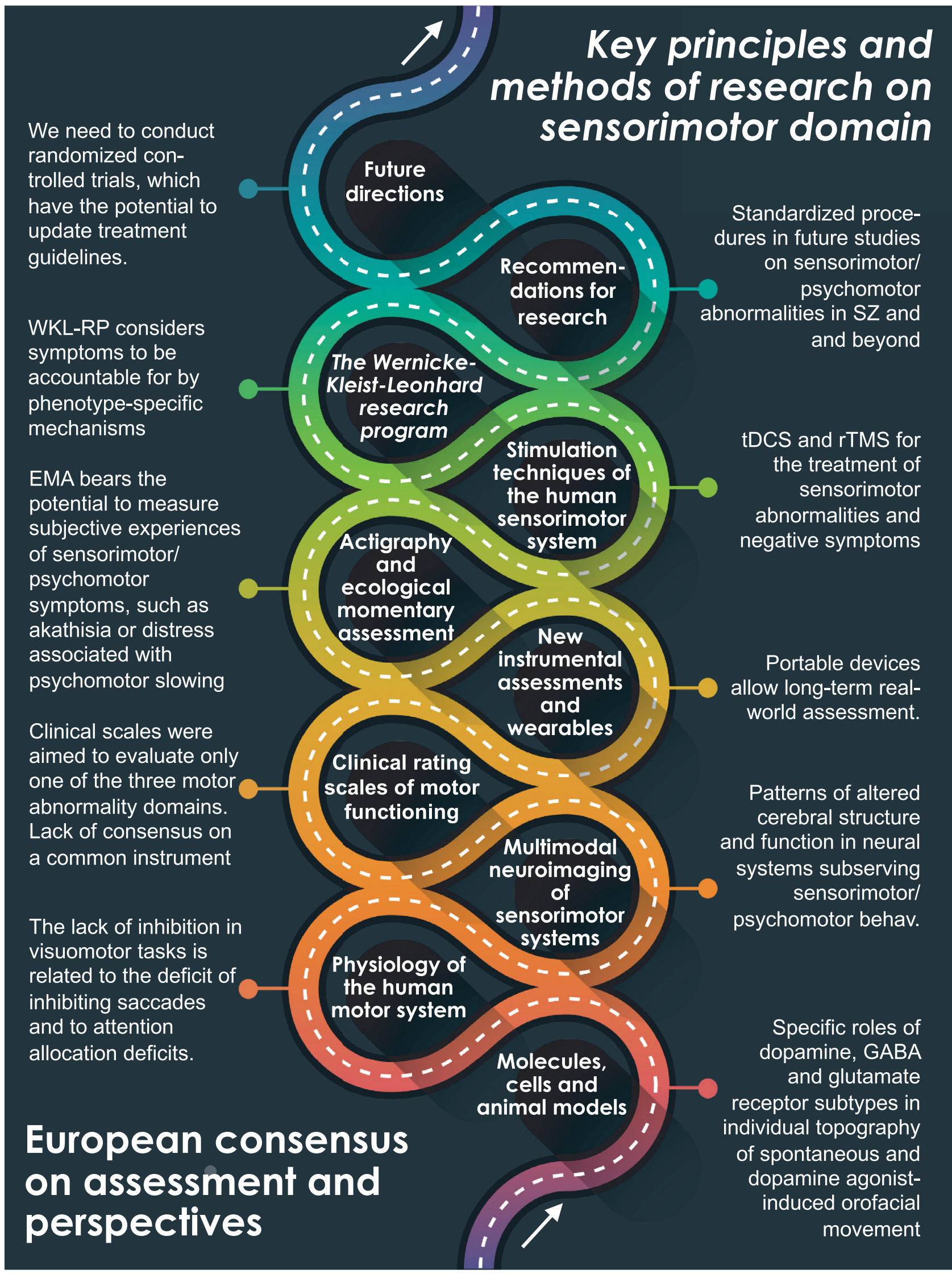

Fig. 1 Overview of the key principles and methods of neuroscientific research into sensorimotor domain in schizophrenia and other psychoses. 


\subsection{Physiology of the human sensorimotor system}

Behavioural sensorimotor abnormalities are well identified in SZ (Wolff and O'Driscoll, 1999) at different time points of disease development, spanning early prodromal to late disease stage (Grootens et al., 2009; Manschreck et al., 2004). These sensorimotor alterations are readily quantifiable and may relate to a higher risk of developing psychosis, since some can be observed in siblings. Consequently, the study of the mechanisms underlying these abnormalities will further aid understanding of pathophysiological mechanisms, illness severity and the risk of developing SZ (Carment et al., 2019; Manschreck et al., 2015; Walther et al., 2016; Wolff and O'Driscoll, 1999). There is a growing interest in connecting underlying mechanisms of sensorimotor abnormalities with other behavioural deficits - such as cognitive deficits - and symptoms. Motor and sensorimotor abnormalities are observed during movement generation and control, for instance during prediction and movement preparation (Dupin et al., 2019) and during online reactive control (Caligiuri and Lohr, 1994; Carment et al., 2019; DelevoyeTurrell et al., 2002; Teremetz et al., 2014). Furthermore, studies indicate that both processes are disturbed: preparation (relying on anticipation), and online control (relying on sensory selection and integration and the production of an adequate response).

In terms of neural control, the motor system functions according to a balance between inhibitory and excitatory processes. Imbalance here can lead to deficits in motor behaviours. The excitation/inhibition activity and balance can be measured during a motor task using transcranial magnetic stimulation (TMS) or electroencephalography (EEG), for instance during simple force control, Go/NoGo or saccadic eye movement tasks. Several studies have found deficits of cortical inhibitory modulation in SZ using EEG (Kiehl et al., 2000) and TMS (Carment et al., 2019; Daskalakis et al., 2002; Lindberg et al., 2016), which were related to symptom severity (Liu et al., 2009). In particular, TMS studies of cortical inhibition within the motor cortex (M1) point to a deficit in the modulation of GABAergic inhibition (Carment et al., 2019; Daskalakis et al., 2008; Lindberg et al., 2016; Wobrock et al., 2009).

At the neural level, psychomotor abnormalities might also be captured using EEG and event-related potentials (ERPs). The movement-related cortical potentials, and above all the ones posited to reflect preparation to voluntary movements, e.g. the lateralized readiness potential (LRP)) within sensorimotor regions (Coles, 1989; Kappenman et al., 2016), and the contingent negative variation (CNV) (Walter et al., 1964) might be of special interest for the examination of sensorimotor/psychomotor abnormalities. According to a recent meta-analysis (Osborne et al., 2020), CNV blunting might be a neural marker of psychomotor dysfunction. The LRP is known to be impaired in SZ groups (Kappenman et al., 2012; Karayanidis et al., 2006), but it might be even more or perhaps selectively delayed in catatonic patients (Northoff et al., 2000). However, the specific relationship between sensorimotor abnormalities and movement-related ERPs remains to be elucidated in comparison with other ERPs (Lebedeva et al., 2008).
In visuomotor tasks, lack of inhibition is related to a deficit in inhibiting saccades and to attention allocation deficits (Carment et al., 2019; Dupin et al., 2019), while lack of modulation of excitability is related to disorganization symptoms (Carment et al., 2019). The deficit of adaptation to uncertainty can be related in the motor domain to a lack of anticipatory modulation of corticospinal excitability in M1 (Dupin et al., 2019) and proactive inhibition deficits (Zandbelt et al., 2011). In conclusion, assessing the modulation and balance of corticospinal excitability and inhibition in the primary motor cortex during different motor tasks could provide novel insights concerning not only sensorimotor abnormalities but also other deficits related to SZ. Since some of these physiological deficits have been observed in healthy siblings of patients, these measures could become tools to identify vulnerability markers and risk for psychosis (Carment et al., 2019; Manschreck et al., 2004).

\subsection{Multimodal neuroimaging of sensorimotor/psychomotor systems}

Though the idea that sensorimotor and psychomotor abnormalities in SZ are caused by pathobiology intrinsic to psychotic illness is not new (Waddington and Crow, 1988), only with the help of magnetic resonance imaging (MRI) we were able to gain deeper knowledge regarding the pathomechanism of sensorimotor and psychomotor abnormalities. Previous MRI studies predominantly focused on neurological soft signs (NSS), tardive dyskinesia (TD), AIM or catatonia (Fig. 2). These studies established neurobiologically plausible models suggesting disturbed corticalsubcortical motor loops underlying NSS (Hirjak et al., 2019), TD (Li et al., 2013) or AIMS (Kindler et al., 2019), as much as they provided new insights into cortical-cortical mechanisms underlying catatonia (Hirjak et al., 2020a, 2015b; Northoff, 2002; Northoff et al., 1995; Richter et al., 2010; Walther et al., 2017a, 2019c; Wasserthal et al., 2020). Fortunately, different techniques of data analysis were used in order to investigate sensorimotor and psychomotor abnormalities in SZ and related psychoses. In addition to classical voxel-based morphometry (VBM) (Hirjak et al., 2015c) and surface-based morphometry (SBM) (Hirjak et al., 2019, 2015a, 2016; Kong et al., 2015), analyses of functional resting-state $M R I$ data measuring intrinsic functional connectivity using blood-oxygen-level dependent (BOLD) effects as well as regional perfusion using arterial spin labeling (ASL) could provide further important insights into aberrant sensorimotor system dysfunction and related psychomotor symptom expression (Hirjak et al., 2018a, 2015b; Thomann et al., 2015; Walther et al., 2017a,b). Although limited, motor-task based functional MRI has also provided a support for altered motor system in SZ (e.g. catatonia Northoff et al., 1999a and NSS Chan et al., 2015). Furthermore, more recently, multimodal MRI data analysis methods integrating (micro)-structural and functional imaging measures (Sui et al., 2012a,b) have been used to expand neuromechanistic understanding of sensorimotor and psychomotor abnormalities in SZ (e.g. NSS, catatonia and Parkinsonism), suggesting a role of combined distributed patterns of altered cerebral structure and function in neural systems subserving coordinated visuospatial func- 


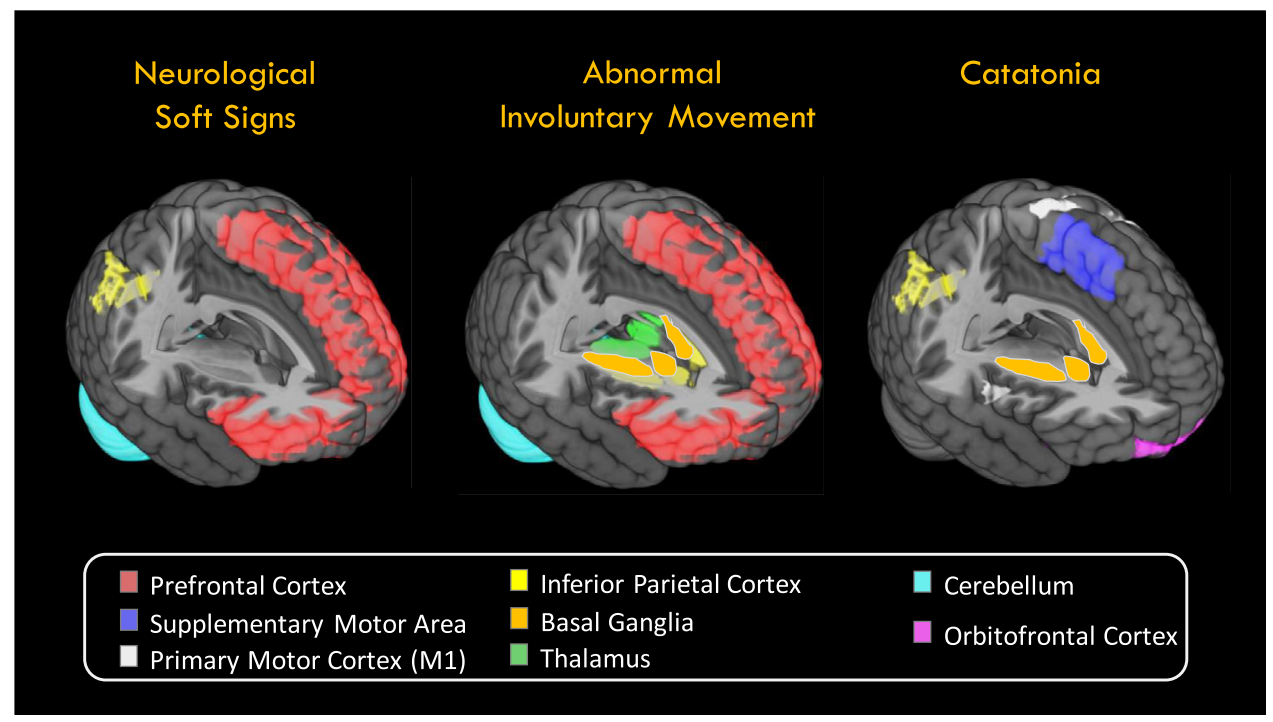

Fig. 2 Brain regions frequently associated with sensorimotor/psychomotor abnormalities in schizophrenia and other psychoses.

tions and sensorimotor/psychomotor behavior (Hirjak et al., 2019, Hirjak et al., 2020b; Wolf et al., 2020). In this regard, a very recent neuroimaging study using relaxometric measures $\left(\mathrm{R} 2{ }^{*}\right)$ showed that iron-loading measures of mainly left-side basal ganglia correlated significantly with EPMS and NSS in first episode psychosis patients (Cuesta et al., 2020).

Although the RDoC initiative has contributed significantly to the introduction of the sensorimotor domain, the concept of "psychomotor" in SZ and other psychoses has been known in clinical and scientific practice since the beginning of 19th century. The "psychomotor" concept involves both domains, namely that of "psycho" (i.e. cognition and emotion) and that of "motor" (movement) (Northoff et al., 2020). At a neuronal level, psychomotor functioning relies on a highly complex interaction between primary nonmotor (e.g., orbitofrontal-affective and default-mode networks) and primary motor (e.g., the dopaminergic-based subcortical-cortical motor circuit) brain networks and neurotransmitters. Some recent MRI studies used a dimensional approach to examine psychomotor abnormalities across different psychiatric disorders (Magioncalda et al., 2020; Martino et al., 2020, 2016, 2018). These studies postulated a transdiagnostic mechanism rooted in aberrant functional connectivity between subcortical structures (substantia nigra, raphe nuclei, thalamus and basal ganglia) and sensorimotor network dysfunction leading to psychomotor abnormalities (Martino et al., 2020; Northoff et al., 2020).

In the next few years, this encouraging development will be extended by further multimodal MRI studies on firstdegree relatives of SZ patients in order to better understand the genetic origin of aberrant sensorimotor and psychomotor functioning in SZ and related psychoses. Since the structural and functional neuroanatomy underlying sensorimotor and psychomotor dysfunction in SZ and other psychoses very likely reflects interplay of genetic, developmental, and environmental factors, future MRI studies should combine parameters from more than one behavioural and imaging modality, and be more firmly imbedded and coordinated among different study centres in order to develop novel diagnostic and prognostic tools of disease progression, as well as for predictive biomarkers of therapeutic response. Prognostic tools based on different parameters of sensorimotor and psychomotor dysfunction might substantially improve the patients' treatment by informing clinical decision-making before the commencement of pharmacological or non-pharmacological treatment and will help clinicians to provide these SZ patients with more intensive rehabilitation (Cuesta et al., 2018b).

\subsection{Behavior, self-reports and clinical rating scales of sensorimotor functioning}

Sensorimotor abnormalities are not included in current diagnostic systems with the exception of abnormal psychomotor behavior, which is included in the A criterion of SZ spectrum disorders in DSM-5 (American Psychiatric Association, 2013). However, a substantial advance in DSM-5 was the inclusion of a catatonia specifier not ascribed to any DSM disorder based on the results of empirical studies (Peralta et al., 2010a). Neither NSS nor EPMS were included within diagnostic criteria for SZ spectrum disorders and only NSS were included within neurodevelopment and attention deficit hyperactivity disorders. Sensorimotor abnormalities are defined and assessed in terms of subjective complaints, psychopathological symptoms and signs (observable, physically examined or elicited by maneuvers), and behaviors. This complexity requires a combination of self-reports, psychopathological and neurological examination for its assessment, with the last of these usually neglected in clinical practice.

Several instruments based on Huber's basic symptom concept examined the subjective perception of sensorimotor disturbances in psychosis by means of self-reports, such as the Frankfurt Complaint Questionnaire (Cuesta et al., 1996a; Rosler et al., 1985; Uttinger et al., 2018), the Examination of Anomalous Self-Experience (Parnas et al., 2005), and the Inventory of Psychotic-Like Anomalous SelfExperiences (Cicero et al., 2017). However, there are no 
studies addressing its comparative validity and very few studies examined its association with objective sensorimotor correlates (Cuesta et al., 1996b). Excellent reviews have been reported on the assessment scales for three types of objective motor abnormalities (Catatonia, EPMS and NSS) (Bombin et al., 2003; Sienaert et al., 2011; van Strien et al., 2015). However, most of the scales were designed to evaluate only one of the three sensorimotor abnormality domains and there is only one validated instrument addressing the assessment of composite motor abnormalities (Cambridge Neurological Inventory) (Chen et al., 1995), which was used mainly by its developers. Moreover, very few empirical studies addressed the comparative validity of sensorimotor abnormality scales (Northoff et al., 1999b) and all of these compared scales within the same domain. There is only one study that aimed to examine the comparative validity of a categorical vs dimensional approach to sensorimotor abnormalities (Peralta and Cuesta, 2011). To date, on the basis of validity, reliability and utility the Northoff Catatonia Rating Scale (Northoff et al., 1999b) and the BushFrancis Catatonia Rating Scale (Bush et al., 1996) for the assessment of catatonic features, the Neurological Evaluation Scale (Buchanan and Heinrichs, 1989) and the Heidelberg Neurological Soft signs Scale (Schroder et al., 1991) for NSS and the Simpson Angus Scale (Simpson and Angus, 1970) and Abnormal Involuntary Movement scale (Guy, 1976) for EPMS are preferred for routine practice and research use. There is an important need for a consensus among experts to define and integrate the whole variety of sensorimotor abnormalities in a common instrument with good psychometric properties and guidelines for use in clinical practice. Moreover, the RDoc matrix (Garvey and Cuthbert, 2017) seems to be a good opportunity to develop instruments for the assessment of the new four domains within the sensorimotor domain: motor action, agency and ownership, habit, and innate motor patterns (Hirjak et al., 2018b).

\subsection{New instrumental assessments and wearables for examination of sensorimotor functioning}

In contrast to psychiatric symptoms, sensorimotor/psychomotor abnormalities can be quantified using technological approaches. Until recently, the assessment of motor symptoms in psychotic disorders has relied on clinical rating scales, but the revolution in technology and information science offers novel approaches for quantifying sensorimotor/psychomotor symptoms. Instrumental measurements have several advantages compared to clinical rating scales. They are objective, accurate and sensitive, overcoming problems such as the inter-observer variability and insensitivity of clinical rating scales. They are therefore capable of detecting subthreshold sensorimotor/psychomotor symptoms (van Harten et al., 2017). Furthermore, electronic data are not prone to non-linearity and floor and ceiling effects, in contrast to clinical rating scales that are typically ordinal by nature with insensitivity to upper or lower extremes (FitzGerald et al., 2018). This may lead to more statistically powerful (parametric) methods. Lastly, instrumental assessment requires little training and can be implemented outside laboratory settings as portable devices allow long-term real-world assessment. Another advantage is that instrumental assessment also collects information on sub-processes and underlying mechanisms. For example, one study evaluated via sensors the gait velocity and stride length in SZ patients and found that reduction in gait velocity was caused by a primary disturbance of stride length regulation and not by cadence (steps per minute) (Putzhammer et al., 2004).

In research settings, instrumental assessment has already been used in various populations and shows that it facilitates diagnostic, prognostic and treatment decisions (FitzGerald et al., 2018; Mittal, 2016; van Harten et al., 2017). Yet instrumental assessment is used only rarely in clinical settings (Dean et al., 2015; Mentzel et al., 2016a; Walther et al., 2009a). However, this may change in the near future due to the high number of sensors available in a smartphone and smartwatch. One sensor is the accelerometer, which is crucial to measuring movement disorders. For example, tremor can be diagnosed with the app 'StudyMyTremor' which assesses the frequency, amplitude, power (i.e. strength) and "steepness" of the main peak in the tremor spectrum. Besides an accelerometer, typical smartphones or smartwatches also include a microphone, camera, gyroscope, pedometer, and can measure ambient temperature, barometer pressure, humidity, heart rate, skin conductance, and have connections such as GPS. For example, these sensors can be used to measure, simultaneously, movement abnormalities (pedometer, accelerometer), surroundings (barometer, temperature, humidity), location (GPS) and sleep (based on breathing and movement). In combination with the Experience Sampling Method (ESM) a motor-mental-cognitive-sleep ecological real-world assessment may be possible (Insel, 2018). Continuous instrumental measurement creates individualized large datasets that require "big data" analytic techniques. Machine learning approaches and network analyses may reveal interacting components and underlying causal relationships of psychomotor functioning in psychotic disorders. In the near future, artificial intelligence may further contribute to these exciting developments, helping health care workers to make more evidence-based and personalized clinical decisions.

\subsection{Actigraphy and ecological momentary assessment}

While expert rating scales have provided reliable estimations of sensorimotor behavior in psychosis, they rely heavily on the observation period and subjects' momentary behaviors. In order to capture sensorimotor behavior in real life, outside the clinic, continuous assessment methods are needed that collect ecologically valid data (van Harten et al., 2017). Actigraphy offers continuous recording of ambulatory data, however, only for a limited number of parameters. These instruments are typically worn on the wrist of the non-dominant arm. Studies in SZ spectrum disorders established associations between a simple marker of total motor activity (i.e. the activity level) with clinical parameters such as psychomotor slowing, negative symptoms, or sedentary behaviors (Docx et al., 2013; Mittal et al., 2013; Walther et al., 2009b; Wichniak et al., 2011). Activity levels are lower in chronic or obese pa- 
tients and in those with more severe negative symptoms (Walther et al., 2014a,b). This objective marker has enabled studies of neuroimaging correlates of psychomotor slowing and readily informs on longitudinal changes (Bracht et al., 2013; Walther et al., 2017a, 2015a). In addition, the temporal pattern or distribution of activity has been investigated in SZ (Sano et al., 2012). Finally, actigraphy on the ankle was able to measure akathisia (Poyurovsky et al., 2000). Thus, actigraphy is an interesting method to collect ecologically valid movement data. However, comparisons across instrument brands are challenging. Future studies will need to establish specific markers to disentangle single pathologies, e.g. Parkinsonism from psychomotor slowing. Another method that could potentially aid capture of sensorimotor abnormalities is ecological momentary assessment (EMA). EMA can be used to track subjective experiences across multiple time points over several days, e.g. randomly 10 times per day for four consecutive days (Kluge et al., 2018). While EMA has the potential to measure subjective experiences of sensorimotor/psychomotor abnormalities, such as akathisia or distress associated with psychomotor slowing, EMA has yet to be applied to measure sensorimotor/psychomotor abnormalities in SZ.

\subsection{Stimulation techniques of the human sensorimotor system}

Sensorimotor abnormalities can be understood as a dysfunction of excitation/inhibition balance within the cerebral motor system (Strik et al., 2017) and the human motor system can be modulated with brain stimulation techniques (Hallett, 2007). Particularly, the premotor and motor cortices are located underneath the cranium and thus readily accessible for non-invasive brain stimulation. Examples include, but are not limited to, transcranial direct current stimulation (tDCS) and repetitive transcranial magnetic stimulation (rTMS). Both techniques may temporarily alter neural activity in specific brain areas. Moreover, deep brain stimulation could be used to modulate aberrant neural activity in the basal ganglia and thalamus. Sensorimotor abnormalities in SZ could be treated via multiple mechanisms, such as increasing focal brain activity, reducing surround noise, or inhibition of single brain regions, or by exerting downstream effects on connectivity within the motor circuit (Lefaucheur et al., 2014). To date, only a few studies have attempted to use brain stimulation to target sensorimotor abnormalities in psychosis. For instance, cerebellar tDCS ameliorated motor learning deficits in subjects with nonclinical psychosis (Gupta et al., 2018). In addition, single sessions of rTMS over the right inferior parietal lobe improved fine motor function in SZ (Walther et al., 2020b). Finally, a large study using 15 sessions of rTMS over the left dorsolateral prefrontal cortex, to treat negative symptoms in SZ, detected beneficial effects on Parkinsonism in a secondary analysis (Kamp et al., 2019). Currently, several groups are conducting studies targeting catatonia or psychomotor slowing in psychosis with rTMS. Preliminary findings are encouraging: a transdiagnostic trial of rTMS for psychomotor slowing in depression and SZ found $1 \mathrm{~Hz}$ rTMS over the SMA to be most effective (Walther et al., 2020a). This field will experience an increase in brain stimulation studies, as noninvasive techniques become widely available, sensorimotor abnormalities are mapped within the cerebral sensorimotor system, and assessments become standardized. Non-invasive brain stimulation has the potential of adding a safe treatment option for the sensorimotor dimension of SZ.

\subsection{The Wernicke-Kleist-Leonhard research program (WKL-RP): psychomotor phenotypes vs dimension(s)}

In contradistinction with the RDoC's 'lumping' of affective and non-affective psychoses, which promotes a normativistic dimensional view of motor manifestations, their splitting into 35 major phenotypes by the WKL-RP gives a completely different perspective (Ungvari and Carroll, 2004). This discrepancy comes from diverging etiological a priori: the WKL-RP challenges the "unique mechanism" thesis and considers symptoms to be accountable for by phenotypespecific mechanisms. Hence it looks for symptom-complexes that, beyond the mere symptoms' co-occurrence, further considers their specific configurations (Foucher et al., 2020). For instance, akinesia (inhibition of psychomotor processes that are coordinating drive, affect, will and automatic routines Magioncalda et al., 2020), retarded catatonia (Walther et al., 2017a and spontaneous Parkinsonism Pappa and Dazzan, 2009) could result from anomalies in any of the three major domains that drive human behaviors: affect, thought, and psychomotricity. In particular, psychomotricity drives expressive and reactive movements, while changes in other domains primarily alter voluntary actions (Foucher et al., 2020).

The WKL-RP separates high-level psychomotor functions from lower-level motor systems on which most NSS and EPMS are mapped. Psychomotricity can be globally dysregulated resulting in purely quantitative changes as in motility psychosis, or some of its systems might be malfunctioning, resulting in qualitative changes such as waxy flexibility or Mitgehen. Within the WKL-RP, distortions of motions' natural flow accounted for by the combined occurrence of intrusive movements and postural stiffness, i.e. parakinesias, are suggestive of psychomotor disintegration. Unfortunately, they remain poorly known outside of WKL-trained clinicians, and hence go mostly unrecognized and not systematically looked for; only a small part might be described as grimacing, mannerism (Ungvari and Carroll, 2004) or spontaneous dyskinesia (Pappa and Dazzan, 2009). The mutual sharing of experience promoted by the ECSP might allow parakinesias to be integrated in a comprehensive clinical rating scale, allowing their systematic screening for the first time.

The WKL-RP distinguishes several primarily psychomotor phenotypes (Krahl et al., 1998). Motility psychosis, one form of cycloid psychosis, exclusively presents as primary hyperkinetic and akinetic episodes that enjoy full remission (Leonhard, 1999a). Motility psychosis accounts for $3 / 4$ of the 32 case-reports labeled as "periodic catatonia" in the international literature (Pfuhlmann et al., 2020). Importantly however, the WKL-RP do not refer to periodic catatonia as the mere recurrence of DSM-catatonic episodes. Beyond these mere quantitative changes, i.e. hy- 
perkinesia and/or akinesia, acute states of periodic catatonia are further characterized by miscellaneous psychomotor distortions that are easily overlooked in instances of too salient, yet unspecific, schizoaffective features. In the long run, WKL-periodic catatonia is characterized by the progressive buildup of a residual deficit state which is not the case in motility psychosis (Leonhard, 1999b). Finally, systems catatonias are early-onset forms which after few years of unspecific manifestations (process phase), progress towards clear-cut life-stable symptom-complexes (Leonhard, 1999c). In the WKL-RP, “catatonia” only refers to the psychomotor phenotypes with a residuum, i.e. periodic and system catatonias. Beyond their clinical characteristics, these differ in their response to antipsychotics (60 vs 1\%) (Ban, 1990) and anti-catatonic treatments (Ungvari et al., 1999), hereditary burden ( 27 vs $5 \%$ affected $1^{\circ}$-relatives) (Stober, 2001) and exposure to prenatal infections (8 vs 34\%) (Stober et al., 2002). Following WKL-RP's disjunctive prediction of a phenotype-dependent pathophysiology, periodic catatonia was specifically associated with left pre-motor hyper-perfusions (Foucher et al., 2019, 2018b). The first use of these anomalies as diagnostic biomarker (Foucher et al., 2019, 2018b) has been recently replicated (de Billy et al., 2020) while their modulation with rTMS led to clinically significant improvement of the periodic catatonia's residuum (Foucher et al., 2018a). Yet the same anomalies and the same rTMS effects were also reported with the retarded catatonia (Walther et al., 2017a) and the psychomotor slowing dimensions (Walther et al., 2020a). A cross-cutting objective of the ECSP would be to differentiate between such competing interpretations, i.e. categorical vs dimensional.

\section{Future directions and recommendations for research}

The sensorimotor research outlined above is of considerable clinical importance in SZ, given that sensorimotor abnormalities may cause significant distress. Furthermore, objective monitoring of sensorimotor behaviors informs clinical staging, illness trajectories, and current state of other symptom dimensions. Finally, noninvasive brain stimulation holds promise in alleviating some of these problematic behaviors, increasing patients' quality of life.

Research on movement disorder and sensorimotor/psychomotor functioning in SZ and other psychoses explores key behaviors and brain circuits that are relevant for multiple disorders, adding value in the RDoC sensorimotor domain. Specific sensorimotor research in psychosis is needed for disentangling the complex interaction between the RDoC sensorimotor domain and other RDoC non-motor domains (e.g. cognition and emotion). The use of the above mentioned advanced technologies opens a window to examine the neurodevelopmental trajectory of sensorimotor/psychomotor abnormalities prior to the first (positive or negative) symptoms of psychosis, but also allows for accessing a behavioral readout of other relevant symptom dimensions, e.g. disorganization or later negative symptoms (Fig. 1). This research effort should also focus on the relationship between spontaneous and treatment emergent sensorimotor/psychomotor abnormalities (Peralta and Cuesta, 2010). Success of large-scale and well-powered studies will emphasize the predictive value of sensorimotor/psychomotor functioning in monitoring the course of the disorder (Sambataro et al., 2020) and help to better understand the modulatory effects of treatment and chronicity on spontaneous sensorimotor/psychomotor abnormalities. Finally, the field should start running interventional studies to ameliorate aberrant sensorimotor behavior, testing pharmacology, exercise, and brain stimulation. After a set of pilot and proof-of-principle studies, we need to conduct randomized controlled trials, which have the potential to update treatment guidelines. Focusing on the clinical impact of sensorimotor behavior is central and will be of interest to psychiatrists (Mittal and Walther, 2019).

Various methodological strategies in previous studies have led to partly contrary results and differing conclusions. In order to standardize procedures in future studies on sensorimotor/psychomotor abnormalities the authors of this consensus paper have formulated the following recommendations:

(1) Clinical rating scales and standardized instrumental assessments, including EMA approaches, should be used to measure sensorimotor dysfunction in SZ and related psychoses. If possible, as many different domains (NSS, dyskinesia, Parkinsonism, catatonia, akathisia, etc.) as possible should be examined under various alternative frameworks (dimension, WKL-RP, etc.) within the study sample. The definition of the respective sensorimotor/psychomotor abnormalities needs to be specified.

(2) It is of fundamental importance to report inter-rater reliability within behavioral studies and test-retest reliability for MRI studies on sensorimotor/psychomotor dysfunction. Selected raters must have clinical experience, be highly trained and be given enough time to examine the study subjects. In particular, clinical experience helps to assess correctly the whole spectrum of sensorimotor/psychomotor abnormalities, including less typical ones such as parakinesias. Raters must have seen both subtle dyskinesias and severe EPMS or TD to correctly assess the severity (clinical expression) of sensorimotor/psychomotor signs and symptoms. Even healthy subjects may have subtle dyskinesias. In order to achieve these goals, as in the neurology of movement disorders, videotaping of patients should be promoted in the sharing of experience and as teaching material. Also, a standardization of structural and functional MRI acquisition and processing protocols across centers will increase the replicability and the possibility of performing meta- and mega-analyses.

(3) It would be best to study antipsychotic-naïve subjects. If this is not possible, it is essential to report the lifetime and/or daily dose of antipsychotic medication. These individual daily doses should be converted into olanzapine equivalents according to the classical mean dose method presented by Leucht and colleagues (Leucht et al., 2015). This approach offers the possibility to consider also newer antipsychotics (in comparison to the method presented by Woods (Woods, 2003)). Furthermore, it could be an opportunity to contradistinguish endogenous from secondary (e.g. antipsychoticinduced) sensorimotor/psychomotor abnormalities. 
(4) Conduct a MRI on each study sample when possible. Structural [e.g. three-dimensional magnetizationprepared rapid gradient-echo (3D-MPRAGE) images] and functional scans (resting-state and combined BOLDASL fMRI) take a very short time (approximately $11 \mathrm{~min}$ ) and can provide useful data.

(5) There is no consensus on the analytical approach to be adopted or the specific covariates that need to be considered when focusing on sensorimotor/psychomotor abnormalities in SZ and other psychoses. Due to associations with sensorimotor behavior, age, illness chronicity, and exposure to antipsychotic and anti-catatonic drugs (e.g. benzodiazepines) should be considered. However, the question of whether a covariate should be adjusted for, provided it does not lie on the causal pathway, depends both on how well the study groups are balanced with respect to the covariate and how strongly the covariate is associated with the outcome (Barnes et al., 2010; Hyatt et al., 2020). In some cases, it is recommended to report the results of betweengroup analyses and correlations with and without covariates.

(6) Carefully address the limitations of each study. Other researchers can learn something from the work and improve procedures in future studies.

(7) Last but not least, it is recommended to conduct longterm transdiagnostic studies to assess the clinical (bedside) value of sensorimotor/psychomotor dysfunction in psychiatric disorders.

\section{Conclusion}

Understanding the sensorimotor domain in SZ may have broader (transdiagnostic) implications. For instance, the concept of movement disorder as an intrinsic component of SZ and related psychotic disorders is integral to corticalbasal ganglia-thalamocortical/cerebellar network dysfunction implicated in the psychopathology of these disorders. It may generalize from movement disorder in psychotic illness to encompass also psychotic illness in movement disorders. By way of example, just as movement disorder in SZ was long considered to be essentially an adverse effect of treatment with antipsychotic drugs, so psychosis in Parkinson's disease (PD) was long considered to be essentially an adverse effect of treatment with levodopa (Ffytche et al., 2017; Ravina et al., 2007). Subsequently, just as movement disorder and sensorimotor/psychomotor abnormalities are now recognized to be an integral feature of SZ, so psychosis is now recognized to be an integral feature of PD (Waddington, 2020). It appears that parkinsonian-like movement disorder in SZ and SZ-like psychosis in PD may reflect site- and time-dependent dysfunction in a common cortical-basal ganglia-thalamocortical/cerebellar network and that such a concept may generalize across the spectrum of psychiatric and neurological disorders in which psychosis and movement disorders (incl. sensorimotor/psychomotor abnormalities) are encountered (Waddington, 2020). Overall, the systematic investigation of the sensorimotor domain in SZ and other psychoses offers a unique opportunity to better understand patients' behavior in both healthy and ill states. In the future, through a better understanding of patients' behavior, relevant diagnostic approaches and therapeutic options should be developed. The ECSP and its participants hope others will join us in the scientific journey to coming closer to these goals.

\section{Role of the funding source}

This work was supported by the German Research Foundation (DFG) (grant number DFG HI 1928/2-1 to D.H. and R.C.W.), Department of Health of the Government of Navarra (grants 11/101 and 87/2014) and the Carlos III Health Institute (FEDER Funds) from the Spanish Ministry of Economy and Competitivity (grants 11/02831, 14/01621 and 16/02148), the Swiss National Science Foundation (grants 182469 and 184717 to S.W.) and the French Programme Hospitalier de Recherche Clinique national (DGS 2005/0543 to J.R.F.).

\section{Contributors}

SW and DH designed and wrote the first draft of this consensus paper. SW, KS and WS wrote Sections 3.6. and 3.7. PNH and LEP wrote Section 3.5. JLW wrote Section 3.1. MJC and VP wrote Section 3.4. DH, RCW, KMK and FS wrote Section 3.3. LD wrote Section 3.2. JRF wrote Section 3.8. All authors contributed to and have approved the final manuscript.

The funding sources had no further role in study design; in the collection, analysis and interpretation of data; in the writing of the report; and in the decision to submit the paper for publication.

\section{Conflict of Interest}

Dr. Walther has received honoraria from Janssen, Neurolite, Lundbeck, Otsuka, and Sunovion in the past 36 months. The authors have declared that there are no conflicts of interest in relation to the subject of this study.

\section{Acknowledgments}

None.

\section{References}

American Psychiatric Association, 2013. Diagnostic and Statistical Manual of Mental Disorders, fifth ed. American Psychiatric Publishing, Washington, DC.

Ban, T.A., 1990. Clinical pharmacology and Leonhard's classification of endogenous psychoses. Psychopathology 23, 331-338.

Barnes, J., Ridgway, G.R., Bartlett, J., Henley, S.M., Lehmann, M., Hobbs, N., Clarkson, M.J., MacManus, D.G., Ourselin, S., Fox, N.C., 2010. Head size, age and gender adjustment in MRI studies: a necessary nuisance? Neuroimage 53, 1244-1255.

Bernard, J.A., Mittal, V.A., 2014. Cerebellar-motor dysfunction in schizophrenia and psychosis-risk: the importance of regional cerebellar analysis approaches. Front. Psychiatry 5, 160. 
Bombin, I., Arango, C., Buchanan, R.W., 2003. Assessment tools for soft signs-a review of the major scales used in research on neurological soft signs in schizophrenia, with recommendations for future directions of soft sign assessment. Psychiatr. Ann. 33, 170-180.

Bracht, T., Schnell, S., Federspiel, A., Razavi, N., Horn, H., Strik, W., Wiest, R., Dierks, T., Muller, T.J., Walther, S., 2013. Altered cortico-basal ganglia motor pathways reflect reduced volitional motor activity in schizophrenia. Schizophr. Res. 143, 269-276.

Buchanan, R.W., Heinrichs, D.W., 1989. The Neurological Evaluation Scale (NES): a structured instrument for the assessment of neurological signs in schizophrenia. Psychiatry Res. 27, 335-350.

Bush, G., Fink, M., Petrides, G., Dowling, F., Francis, A., 1996. Catatonia. I. Rating scale and standardized examination. Acta Psychiatr. Scand. 93, 129-136.

Caligiuri, M.P., Lohr, J.B., 1994. A disturbance in the control of muscle force in neuroleptic-naive schizophrenic patients. Biol. Psychiatry 35, 104-111.

Carment, L., Dupin, L., Guedj, L., Teremetz, M., Krebs, M.O., Cuenca, M., Maier, M.A., Amado, I., Lindberg, P.G., 2019. Impaired attentional modulation of sensorimotor control and cortical excitability in schizophrenia. Brain 142, 2149-2164.

Chan, R.C., Huang, J., Zhao, Q., Wang, Y., Lai, Y.Y., Hong, N., Shum, D.H., Cheung, E.F., Yu, X., Dazzan, P., 2015. Prefrontal cortex connectivity dysfunction in performing the Fist-EdgePalm task in patients with first-episode schizophrenia and non-psychotic first-degree relatives. Neuroimage Clin. 9, 411-417.

Chen, E.Y., Shapleske, J., Luque, R., McKenna, P.J., Hodges, J.R., Calloway, S.P., Hymas, N.F., Dening, T.R., Berrios, G.E., 1995. The Cambridge Neurological Inventory: a clinical instrument for assessment of soft neurological signs in psychiatric patients. Psychiatry Res. 56, 183-204.

Chouinard, G., Annable, L., Ross-Chouinard, A., Nestoros, J.N., 1979. Factors related to tardive dyskinesia. Am. J. Psychiatry 136, 79-82.

Cicero, D.C., Neis, A.M., Klaunig, M.J., Trask, C.L., 2017. The Inventory of Psychotic-Like Anomalous Self-Experiences (IPASE): development and validation. Psychol. Assess. 29, 13-25.

Coles, M.G., 1989. Modern mind-brain reading: psychophysiology, physiology, and cognition. Psychophysiology 26, 251-269.

Cuesta, M.J., Garcia de Jalon, E., Campos, M.S., Moreno-Izco, L., Lorente-Omenaca, R., Sanchez-Torres, A.M., Peralta, V., 2018a. Motor abnormalities in first-episode psychosis patients and long-term psychosocial functioning. Schizophr. Res. 200, 97-103.

Cuesta, M.J., Lecumberri, P., Moreno-Izco, L., Lopez-Ilundain, J.M., Ribeiro, M., Cabada, T., Lorente-Omenaca, R., de Erausquin, G., Garcia-Marti, G., Sanjuan, J., Sanchez-Torres, A.M., Gomez, M., Peralta, V., 2020. Motor abnormalities and basal ganglia in first-episode psychosis (FEP). Psychol. Med. 1-12.

Cuesta, M.J., Moreno-Izco, L., Ribeiro, M., Lopez-Ilundain, J.M., Lecumberri, P., Cabada, T., Lorente-Omenaca, R., Sanchez-Torres, A.M., Gomez, M.S., Peralta, V., 2018b. Motor abnormalities and cognitive impairment in first-episode psychosis patients, their unaffected siblings and healthy controls. Schizophr. Res. 200, 50-55.

Cuesta, M.J., Peralta, V., 2018. Modeling neuromotor pathology in schizophrenia: a window to brain mechanisms and clinical insight into the syndrome. Schizophr. Res. 200, 1-4.

Cuesta, M.J., Peralta, V., Irigoyen, I., 1996a. Factor analysis of the Frankfurt Complaint Questionnaire in a Spanish sample. Psychopathology 29, 46-53.

Cuesta, M.J., Peralta, V., Juan, J.A., 1996b. Abnormal subjective experiences in schizophrenia: its relationships with neuropsychological disturbances and frontal signs. Eur. Arch. Psychiatry Clin. Neurosci. 246, 101-105.
Cuesta, M.J., Sanchez-Torres, A.M., de Jalon, E.G., Campos, M.S., Ibanez, B., Moreno-Izco, L., Peralta, V., 2014. Spontaneous parkinsonism is associated with cognitive impairment in antipsychotic-naive patients with first-episode psychosis: a 6-month follow-up study. Schizophr. Bull. 40, 1164-1173.

Daskalakis, Z.J., Christensen, B.K., Chen, R., Fitzgerald, P.B., Zipursky, R.B., Kapur, S., 2002. Evidence for impaired cortical inhibition in schizophrenia using transcranial magnetic stimulation. Arch. Gen. Psychiatry 59, 347-354.

Daskalakis, Z.J., Christensen, B.K., Fitzgerald, P.B., Moller, B., Fountain, S.I., Chen, R., 2008. Increased cortical inhibition in persons with schizophrenia treated with clozapine. J. Psychopharmacol. 22, 203-209.

de Billy, C., Jeanjean, L.C., Mainberger, O., Obrecht, A., Clauss, J.M.E., Schorr, B., Moog, C., P.L., d.S., Lamy, J., Noblet, V., Landré, L., Kempf, E., Berna, F., Sauleau, E.A., Foucher, J.R., 2020. Bayesian updating of the diagnostic biomarker for periodic catatonia". (submitted).

Dean, D.J., Kent, J.S., Bernard, J.A., Orr, J.M., Gupta, T., Pelletier-Baldelli, A., Carol, E.E., Mittal, V.A., 2015. Increased postural sway predicts negative symptom progression in youth at ultrahigh risk for psychosis. Schizophr. Res. 162, 86-89.

Delevoye-Turrell, Y., Giersch, A., Danion, J.M., 2002. A deficit in the adjustment of grip force responses in schizophrenia. Neuroreport 13, 1537-1539.

Docx, L., Sabbe, B., Provinciael, P., Merckx, N., Morrens, M., 2013. Quantitative psychomotor dysfunction in schizophrenia: a loss of drive, impaired movement execution or both? Neuropsychobiology $68,221-227$.

Dupin, L., Carment, L., Guedj, L., Cuenca, M., Krebs, M.O., Maier, M.A., Amado, I., Lindberg, P.G., 2019. Predictive modulation of corticospinal excitability and implicit encoding of movement probability in schizophrenia. Schizophr. Bull. 45, 1358-1366.

Dutschke, L.L., Stegmayer, K., Ramseyer, F., Bohlhalter, S., Vanbellingen, T., Strik, W., Walther, S., 2018. Gesture impairments in schizophrenia are linked to increased movement and prolonged motor planning and execution. Schizophr. Res. 200, 42-49.

Ffytche, D.H., Creese, B., Politis, M., Chaudhuri, K.R., Weintraub, D., Ballard, C., Aarsland, D., 2017. The psychosis spectrum in Parkinson disease. Nat. Rev. Neurol 13, 81-95.

Filatova, S., Koivumaa-Honkanen, H., Hirvonen, N., Freeman, A., Ivandic, I., Hurtig, T., Khandaker, G.M., Jones, P.B., Moilanen, K., Miettunen, J., 2017. Early motor developmental milestones and schizophrenia: a systematic review and meta-analysis. Schizophr. Res. 188, 13-20.

Filatova, S., Koivumaa-Honkanen, H., Khandaker, G.M., Lowry, E., Nordstrom, T., Hurtig, T., Moilanen, K., Miettunen, J., 2018. Early motor developmental milestones and schizotypy in the Northern Finland Birth cohort study 1966. Schizophr. Bull. 44, 1151-1158.

FitzGerald, J.J., Lu, Z., Jareonsettasin, P., Antoniades, C.A., 2018. Quantifying motor impairment in movement disorders. Front. Neurosci. 12, 202.

Foucher, J.R., de Billy, C., Jeanjean, L.C., Obrecht, A., Mainberger, O., Clauss, J.M.E., Schorr, B., Lupu, M.C., de Sousa, P.L., Lamy, J., Noblet, V., Sauleau, E.A., Landre, L., Berna, F., 2019. A brain imaging-based diagnostic biomarker for periodic catatonia: preliminary evidence using a Bayesian approach. Neuropsychobiology 1-14.

Foucher, J.R., de Billy, C., Mainberger, O., Schorr, B., Clauss, J., Berna, F., 2018a. Personalized rTMS improves chronic and treatment resistant catatonias - a proof of concept study. 3rd European Conference on Brain Stimulation in Psychiatry "From Mechanisms to Medicine". Lyon 18th to 20th October 2018.

Foucher, J.R., Gawlik, M., Roth, J.N., De Billy, C.C., Jeanjean, L.C., Obrecht, A., Mainberger, O., Clauss, J.E.M., 
Elowe, J., Weibel, S., Schorr, B., Cetkovich, M., Morra, C., Rebok, F., Ban, T.A., Bollmann, B., Roser, M.M., Hanke, M.S., Jabs, B.E., Franzek, E.J., Berna, F., Pfuhlmann, B., 2020. Wernicke-Kleist-Leonhard phenotypes of endogenous psychoses: a review of their validity. Dialog. Clin. Neurosci. 22 (1), 37-49.

Foucher, J.R., Zhang, Y.F., Roser, M., Lamy, J., De Sousa, P.L., Weibel, S., Vidailhet, P., Mainberger, O., Berna, F., 2018b. A double dissociation between two psychotic phenotypes: periodic catatonia and cataphasia. Prog. Neuropsychopharmacol. Biol. Psychiatry 86, 363-369.

Garvey, M.A., Cuthbert, B.N., 2017. Developing a motor systems domain for the NIMH RDoC program. Schizophr. Bull. 43, 935-936.

Grootens, K.P., Vermeeren, L., Verkes, R.J., Buitelaar, J.K., Sabbe, B.G., van Veelen, N., Kahn, R.S., Hulstijn, W., 2009. Psychomotor planning is deficient in recent-onset schizophrenia. Schizophr. Res. 107, 294-302.

Gupta, T., Dean, D.J., Kelley, N.J., Bernard, J.A., Ristanovic, I., Mittal, V.A., 2018. Cerebellar transcranial direct current stimulation improves procedural learning in nonclinical psychosis: a double-blind crossover study. Schizophr. Bull. 44, 1373-1380.

Guy, W., 1976. Assessment Manual for Psychopharmacology. Rockville/ Ts, NIH Psychopharmacology Research, pp. 76-338.

Hallett, M., 2007. Transcranial magnetic stimulation: a primer. Neuron 55, 187-199.

Hirjak, D., Kubera, K.M., Northoff, G., Fritze, S., Bertolino, A.L., Topor, C.E., Schmitgen, M.M., Wolf, R.C., 2019. Cortical contributions to distinct symptom dimensions of catatonia. Schizophr. Bull. 45, 1184-1194.

Hirjak, D., Kubera, K.M., Sambataro, F., Wolf, R.C., 2020. Motor domain in psychotic disorders: the rebirth of a concept. Eur. Arch. Psychiatry Clin. Neurosci. 270 (3), 399-400. doi:10.1007/ s00406-019-01036-7, Epub 2019 Jun 25. PMID: 31240444.

Hirjak, D., Kubera, K.M., Thomann, P.A., Wolf, R.C., 2018a. Motor dysfunction as an intermediate phenotype across schizophrenia and other psychotic disorders: progress and perspectives. Schizophr. Res. 200, 26-34.

Hirjak, D., Kubera, K.M., Wolf, R.C., Northoff, G., 2020a. Going back to Kahlbaum's Psychomotor (and GABAergic) origins: is catatonia more than just a motor and dopaminergic syndrome? Schizophr. Bull. 46 (2), 272-285. doi:10.1093/schbul/sbz074.

Hirjak, D., Kubera, K.M., Wolf, R.C., Thomann, A.K., Hell, S.K., Seidl, U., Thomann, P.A., 2015a. Local brain gyrification as a marker of neurological soft signs in schizophrenia. Behav. Brain Res. 292, 19-25.

Hirjak, D., Meyer-Lindenberg, A., Fritze, S., Sambataro, F., Kubera, K.M., Wolf, R.C., 2018b. Motor dysfunction as research domain across bipolar, obsessive-compulsive and neurodevelopmental disorders. Neurosci. Biobehav. Rev. 95, 315-335.

Hirjak, D., Rashidi, M., Fritze, S., Bertolino, A.L., Geiger, L.S., Zang, Z., Kubera, K.M., Schmitgen, M.M., Sambataro, F., Calhoun, V.D., Weisbrod, M., Wolf, R.C., 2019. Patterns of coaltered brain structure and function underlying neurological soft signs in schizophrenia spectrum disorders. Hum. Brain Mapp. 40 (17), 5029-5041. doi:10.1002/hbm.24755, Epub 2019 Aug 12.

Hirjak, D., Rashidi, M., Kubera, K.M., Northoff, G., Fritze, S., Schmitgen, M.M., Sambataro, F., Calhoun, V.D., Wolf, R.C., 2020b. Multimodal magnetic resonance imaging data fusion reveals distinct patterns of abnormal brain structure and function in catatonia. Schizophr. Bull. 46 (1), 202-210. doi:10.1093/ schbul/sbz042.

Hirjak, D., Thomann, P.A., Kubera, K.M., Wolf, N.D., Sambataro, F., Wolf, R.C., 2015b. Motor dysfunction within the schizophrenia-spectrum: a dimensional step towards an underappreciated domain. Schizophr. Res. 169, 217-233.

Hirjak, D., Wolf, R.C., Kubera, K.M., Stieltjes, B., Maier-Hein, K.H., Thomann, P.A., 2015c. Neurological soft signs in recent-onset schizophrenia: focus on the cerebellum. Prog. Neuropsychopharmacol. Biol. Psychiatry 60, 18-25.
Hirjak, D., Wolf, R.C., Paternoga, I., Kubera, K.M., Thomann, A.K., Stieltjes, B., Maier-Hein, K.H., Thomann, P.A., 2016. Neuroanatomical markers of neurological soft signs in recent-onset schizophrenia and asperger-syndrome. Brain Topogr. 29, 382-394.

Hyatt, C.S., Owens, M.M., Crowe, M.L., Carter, N.T., Lynam, D.R., Miller, J.D., 2020. The quandary of covarying: a brief review and empirical examination of covariate use in structural neuroimaging studies on psychological variables. Neuroimage 205, 116225.

Insel, T.R., 2018. Digital phenotyping: a global tool for psychiatry. World Psychiatry 17, 276-277.

Kamp, D., Engelke, C., Wobrock, T., Wolwer, W., Winterer, G., Schmidt-Kraepelin, C., Gaebel, W., Langguth, B., Landgrebe, M., Eichhammer, P., Frank, E., Hajak, G., Ohmann, C., Verde, P.E., Rietschel, M., Raees, A., Honer, W.G., Malchow, B., Schneider-Axmann, T., Falkai, P., Hasan, A., Cordes, J., 2019. Left prefrontal high-frequency rTMS may improve movement disorder in schizophrenia patients with predominant negative symptoms - a secondary analysis of a sham-controlled, randomized multicenter trial. Schizophr. Res. 204, 445-447.

Kappenman, E.S., Kaiser, S.T., Robinson, B.M., Morris, S.E., Hahn, B., Beck, V.M., Leonard, C.J., Gold, J.M., Luck, S.J., 2012. Response activation impairments in schizophrenia: evidence from the lateralized readiness potential. Psychophysiology 49, 73-84.

Kappenman, E.S., Luck, S.J., Kring, A.M., Lesh, T.A., Mangun, G.R., Niendam, T., Ragland, J.D., Ranganath, C., Solomon, M., Swaab, T.Y., Carter, C.S., 2016. Electrophysiological evidence for impaired control of motor output in schizophrenia. Cerebral cortex 26, 1891-1899.

Karayanidis, F., Nicholson, R., Schall, U., Meem, L., Fulham, R., Michie, P.T., 2006. Switching between univalent task-sets in schizophrenia: ERP evidence of an anticipatory task-set reconfiguration deficit. Clin. Neurophysiol. 117, 2172-2190.

Kent, J.S., Caligiuri, M.P., Skorheim, M.K., Lano, T.J., Mittal, V.A., Sponheim, S.R., 2019. Instrument-based assessment of motor function yields no evidence of dyskinesia in adult first-degree biological relatives of individuals with schizophrenia and schizoaffective disorder. Psychiatry Res. 272, 135-140.

Kiehl, K.A., Smith, A.M., Hare, R.D., Liddle, P.F., 2000. An event-related potential investigation of response inhibition in schizophrenia and psychopathy. Biol. Psychiatry 48, 210-221.

Kindler, J., Michel, C., Schultze-Lutter, F., Felber, G., Hauf, M., Schimmelmann, B.G., Kaess, M., Hubl, D., Walther, S., 2019. Functional and structural correlates of abnormal involuntary movements in psychosis risk and first episode psychosis. Schizophr. Res..

Kluge, A., Kirschner, M., Hager, O.M., Bischof, M., Habermeyer, B., Seifritz, E., Walther, S., Kaiser, S., 2018. Combining actigraphy, ecological momentary assessment and neuroimaging to study apathy in patients with schizophrenia. Schizophr. Res. 195, 176-182.

Kong, L., Herold, C.J., Lasser, M.M., Schmid, L.A., Hirjak, D., Thomann, P.A., Essig, M., Schroder, J., 2015. Association of cortical thickness and neurological soft signs in patients with chronic schizophrenia and healthy controls. Neuropsychobiology 71, 225-233.

Krahl, A., Schifferdecker, M., Beveridge, A., 1998. Carl Wernicke and the concept of 'elementary symptom'. Hist. Psychiatry 9, 503-508.

Lebedeva, I.S., Kaleda, V.G., Barkhatova, A.N., 2008. Neurophysiological characteristics of cognitive functions in patients with first episodes of endogenous psychosis. Neurosci. Behav. Physiol. 38, 259-267.

Lefaucheur, J.P., Andre-Obadia, N., Antal, A., Ayache, S.S., Baeken, C., Benninger, D.H., Cantello, R.M., Cincotta, M., de Carvalho, M., De Ridder, D., Devanne, H., Di Lazzaro, V., Filipovic, S.R., Hummel, F.C., Jaaskelainen, S.K., Kimiskidis, V.K., 
Koch, G., Langguth, B., Nyffeler, T., Oliviero, A., Padberg, F., Poulet, E., Rossi, S., Rossini, P.M., Rothwell, J.C., Schonfeldt-Lecuona, C., Siebner, H.R., Slotema, C.W., Stagg, C.J., VallsSole, J., Ziemann, U., Paulus, W., Garcia-Larrea, L., 2014. Evidence-based guidelines on the therapeutic use of repetitive transcranial magnetic stimulation (rTMS). Clin. Neurophysiol. 125, 2150-2206.

Leonhard, K., 1999a. Hyperkinetic-Akinetic Motility Psychosis. Spinger, Vienna, Austria, pp. 75-81 Classification of Endogenous Psychoses and Their Differentiated Etiology.

Leonhard, K., 1999b. Periodic catatonia., In: Classification of Endogenous Psychoses and their Differentiated Etiology. Springer Vienna, Vienna, pp. 104-112.

Leonhard, K., 1999c. Simple Systematic Schizophrenias: Catatonic forms., In: Classification of Endogenous Psychoses and their Differentiated Etiology. Springer, Vienna, Austria, pp. 114-153.

Leucht, S., Samara, M., Heres, S., Patel, M.X., Furukawa, T., Cipriani, A., Geddes, J., Davis, J.M., 2015. Dose Equivalents for second-generation antipsychotic drugs: the classical mean dose method. Schizophr. Bull. 41, 1397-1402.

Li, C.T., Chou, K.H., Su, T.P., Huang, C.C., Chen, M.H., Bai, Y.M., Lin, C.P., 2013. Gray matter abnormalities in schizophrenia patients with tardive dyskinesia: a magnetic resonance imaging voxel-based morphometry study. PLoS ONE 8, e71034.

Lindberg, P.G., Teremetz, M., Charron, S., Kebir, O., Saby, A., Bendjemaa, N., Lion, S., Crepon, B., Gaillard, R., Oppenheim, C., Krebs, M.O., Amado, I., 2016. Altered cortical processing of motor inhibition in schizophrenia. Cortex 85, 1-12.

Liu, S.K., Fitzgerald, P.B., Daigle, M., Chen, R., Daskalakis, Z.J., 2009. The relationship between cortical inhibition, antipsychotic treatment, and the symptoms of schizophrenia. Biol. Psychiatry 65, 503-509.

Magioncalda, P., Martino, M., Conio, B., Lee, H.C., Ku, H.L., Chen, C.J., Inglese, M., Amore, M., Lane, T.J., Northoff, G., 2020. Intrinsic brain activity of subcortical-cortical sensorimotor system and psychomotor alterations in schizophrenia and bipolar disorder: a preliminary study. Schizophr. Res..

Manschreck, T.C., Chun, J., Merrill, A.M., Maher, B.A., Boshes, R.A., Glatt, S.J., Faraone, S.V., Tsuang, M.T., Seidman, L.J., 2015. Impaired motor performance in adolescents at familial high-risk for schizophrenia. Schizophr. Res. 168, 44-49.

Manschreck, T.C., Maher, B.A., Candela, S.F., 2004. Earlier age of first diagnosis in schizophrenia is related to impaired motor control. Schizophr. Bull. 30, 351-360.

Martino, M., Magioncalda, P., Conio, B., Capobianco, L., Russo, D., Adavastro, G., Tumati, S., Tan, Z., Lee, H.C., Lane, T.J., Amore, M., Inglese, M., Northoff, G., 2020. Abnormal functional relationship of sensorimotor network with neurotransmitter-related nuclei via subcortical-cortical loops in manic and depressive phases of bipolar disorder. Schizophr. Bull. 46, 163-174.

Martino, M. , Magioncalda, P., Huang, Z., Conio, B., Piaggio, N., Duncan, N.W., Rocchi, G., Escelsior, A., Marozzi, V., Wolff, A., Inglese, M., Amore, M., Northoff, G., 2016. Contrasting variability patterns in the default mode and sensorimotor networks balance in bipolar depression and mania. Proc. Natl. Acad. Sci. U.S.A. 113, 4824-4829.

Martino, M., Magioncalda, P., Yu, H., Li, X., Wang, Q., Meng, Y., Deng, W., Li, Y., Li, M., Ma, X., Lane, T., Duncan, N.W., Northoff, G., Li, T., 2018. Abnormal resting-state connectivity in a substantia Nigra-related Striato-Thalamo-Cortical network in a large sample of first-episode drug-naive patients with schizophrenia. Schizophr. Bull. 44, 419-431.

Mentzel, T.Q., Lieverse, R., Levens, A., Mentzel, C.L., Tenback, D.E., Bakker, P.R., Daanen, H.A.M., van Harten, P.N., 2016a. Reliability and validity of an instrument for the assessment of bradykinesia. Psychiatry Res. 238, 189-195.

Mentzel, T.Q., Mentzel, C.L., Mentzel, S.V., Lieverse, R., Daanen, H.A., van Harten, P.N., 2016b. Instrumental assessment of Bradykinesia: a comparison between motor tasks. IEEE J. Biomed. Health Inform. 20, 521-526.

Mittal, V.A., 2016. Cross-cutting advancements usher in a new era for motor research in psychosis. Schizophr. Bull. 42, 1322-1325.

Mittal, V.A., Bernard, J.A., Northoff, G., 2017. What can different motor circuits tell us about psychosis? An RDoC Perspective. Schizophr. Bull. 43, 949-955.

Mittal, V.A., Dean, D.J., Bernard, J.A., Orr, J.M., Pelletier-Baldelli, A., Carol, E.E., Gupta, T., Turner, J., Leopold, D.R., Robustelli, B.L., Millman, Z.B., 2014. Neurological soft signs predict abnormal cerebellar-thalamic tract development and negative symptoms in adolescents at high risk for psychosis: a longitudinal perspective. Schizophr. Bull. 40, 1204-1215.

Mittal, V.A., Gupta, T., Orr, J.M., Pelletier-Baldelli, A., Dean, D.J., Lunsford-Avery, J.R., Smith, A.K., Robustelli, B.L., Leopold, D.R., Millman, Z.B., 2013. Physical activity level and medial temporal health in youth at ultra high-risk for psychosis. J. Abnorm. Psychol. 122, 1101-1110.

Mittal, V.A., Walther, S., 2019. As motor system pathophysiology returns to the forefront of psychosis research, clinical implications should hold center stage. Schizophr. Bull. 45, 495-497.

Northoff, G., 2002. What catatonia can tell us about "top-down modulation": a neuropsychiatric hypothesis. Behav. Brain Sci. 25, 555-577 discussion 578-604.

Northoff, G., 2016a. Spatiotemporal psychopathology I: no rest for the brain's resting state activity in depression? Spatiotemporal psychopathology of depressive symptoms. J. Affect. Disord. 190, 854-866.

Northoff, G., 2016b. Spatiotemporal Psychopathology II: how does a psychopathology of the brain's resting state look like? Spatiotemporal approach and the history of psychopathology. J. Affect. Disord. 190, 867-879.

Northoff, G., Braus, D.F., Sartorius, A., Khoram-Sefat, D., Russ, M., Eckert, J., Herrig, M., Leschinger, A., Bogerts, B., Henn, F.A., 1999a. Reduced activation and altered laterality in two neuroleptic-naive catatonic patients during a motor task in functional MRI. Psychol. Med. 29, 997-1002.

Northoff, G., Hirjak, D., Wolf, C., Magioncalda, P., Martino, M., 2020. All roads lead to the motor cortex: psychomotor mechanisms and their biochemical modulation in psychiatric disorders. Molecular Psychiatry, doi:10.1038/s41380-020-0814-5.

Northoff, G., Koch, A., Wenke, J., Eckert, J., Boker, H., Pflug, B., Bogerts, B., 1999b. Catatonia as a psychomotor syndrome: a rating scale and extrapyramidal motor symptoms. Movement Disord. $14,404-416$.

Northoff, G., Kotter, R., Baumgart, F., Danos, P., Boeker, H., Kaulisch, T., Schlagenhauf, F., Walter, H., Heinzel, A., Witzel, T., Bogerts, B., 2004. Orbitofrontal cortical dysfunction in akinetic catatonia: a functional magnetic resonance imaging study during negative emotional stimulation. Schizophr. Bull. 30, 405-427.

Northoff, G., Pfennig, A., Krug, M., Danos, P., Leschinger, A., Schwarz, A., Bogerts, B., 2000. Delayed onset of late movement-related cortical potentials and abnormal response to lorazepam in catatonia. Schizophr. Res. 44, 193-211.

Northoff, G., Wenke, J., Demisch, L., Eckert, J., Gille, B., Pflug, B., 1995. Catatonia: short-term response to lorazepam and dopaminergic metabolism. Psychopharmacology (Berl.) 122, 182-186.

Osborne, K.J., Kraus, B., Lam, P.H., Vargas, T., Mittal, V.A., 2020. Contingent negative variation blunting and psychomotor dysfunction in schizophrenia: a systematic review. Schizophr. Bull..

Pappa, S., Dazzan, P., 2009. Spontaneous movement disorders in antipsychotic-naive patients with first-episode psychoses: a systematic review. Psychol. Med. 39, 1065-1076. 
Parnas, J., Moller, P., Kircher, T., Thalbitzer, J., Jansson, L., Handest, P., Zahavi, D., 2005. EASE: examination of anomalous selfexperience. Psychopathology 38, 236-258.

Peralta, V., Campos, M.S., de Jalon, E.G., Cuesta, M.J., 2010a. DSM-IV catatonia signs and criteria in first-episode, drug-naive, psychotic patients: psychometric validity and response to antipsychotic medication. Schizophr. Res. 118, 168-175.

Peralta, V., Campos, M.S., De Jalon, E.G., Cuesta, M.J., 2010b. Motor behavior abnormalities in drug-naive patients with schizophrenia spectrum disorders. Movement Disord. 25, 1068-1076.

Peralta, V., Cuesta, M.J., 2010. The effect of antipsychotic medication on neuromotor abnormalities in neuroleptic-naive nonaffective psychotic patients: a naturalistic study with haloperidol, risperidone, or olanzapine. Prim Care Companion J. Clin. Psychiatry 12 .

Peralta, V., Cuesta, M.J., 2011. Neuromotor abnormalities in neuroleptic-naive psychotic patients: antecedents, clinical correlates, and prediction of treatment response. Compr. Psychiatry 52, 139-145.

Peralta, V., Cuesta, M.J., 2017. Motor abnormalities: from neurodevelopmental to neurodegenerative through "functional" (Neuro)psychiatric disorders. Schizophr. Bull. 43, 956-971 VolumePages.

Pfuhlmann, B., Gawlik, M., Roth, N.J., de Billy, C., Jeanjean, L.C., Obrecht, A., Mainberger, O., Clauss, J.M.E., Elowe, J., Weibel, S., Schorr, B., Cetkovich, M., Morra, C., Rebok, F., Ban, T., Bollmann, B., Roser, M.M., Hanke, M., Jabs, B.E., Franzek, E.J., Berna, F., Foucher, J.R., 2020. IDC-DSM catatonia disorder and WKL-periodic catatonia phenotype: struggling with (in)commensurability., inhn.org.

Poyurovsky, M., Nave, R., Epstein, R., Tzischinsky, O., Schneidman, M., Barnes, T.R., Weizman, A., Lavie, P., 2000. Actigraphic monitoring (actigraphy) of circadian locomotor activity in schizophrenic patients with acute neuroleptic-induced akathisia. Eur. Neuropsychopharmacol. 10, 171-176.

Putzhammer, A., Heindl, B., Broll, K., Pfeiff, L., Perfahl, M., Hajak, G., 2004. Spatial and temporal parameters of gait disturbances in schizophrenic patients. Schizophr. Res. 69, 159-166.

Quinn, J., Meagher, D., Murphy, P., Kinsella, A., Mullaney, J., Waddington, J.L., 2001. Vulnerability to involuntary movements over a lifetime trajectory of schizophrenia approaches $100 \%$, in association with executive (frontal) dysfunction. Schizophr. Res. 49, 79-87.

Ravina, B., Marder, K., Fernandez, H.H., Friedman, J.H., McDonald, W., Murphy, D., Aarsland, D., Babcock, D., Cummings, J., Endicott, J., Factor, S., Galpern, W., Lees, A., Marsh, L., Stacy, M., Gwinn-Hardy, K., Voon, V., Goetz, C., 2007. Diagnostic criteria for psychosis in Parkinson's disease: report of an NINDS, NIMH work group. Movement Disord. 22, 1061-1068.

Richter, A., Grimm, S., Northoff, G., 2010. Lorazepam modulates orbitofrontal signal changes during emotional processing in catatonia. Hum. Psychopharmacol. 25, 55-62.

Rosler, M., Bellaire, W., Hengesch, G., Kiesling-Muck, H., Carls, W., 1985. [Uncharacteristic "basic" symptoms in the Frankfurt Complaint Questionnaire and their relation to psychopathologic syndromes]. Nervenarzt 56, 259-264.

Sambataro, F., Fritze, S., Rashidi, M., Topor, C.E., Kubera, K.M., Wolf, R.C., Hirjak, D., 2020. Moving forward: distinct sensorimotor abnormalities predict clinical outcome after 6 months in patients with schizophrenia. Eur. Neuropsychopharmacol. (in press).

Sanislow, C.A., Ferrante, M., Pacheco, J., Rudorfer, M.V., Morris, S.E., 2019. Advancing Translational Research Using NIMH Research Domain Criteria and Computational Methods. Neuron 101, 779-782.

Sano, W., Nakamura, T., Yoshiuchi, K., Kitajima, T., Tsuchiya, A., Esaki, Y., Yamamoto, Y., Iwata, N., 2012. Enhanced persistency of resting and active periods of locomotor activity in schizophrenia. PLoS ONE 7, e43539.

Schroder, J., Niethammer, R., Geider, F.J., Reitz, C., Binkert, M., Jauss, M., Sauer, H., 1991. Neurological soft signs in schizophrenia. Schizophr. Res. 6, 25-30.

Sienaert, P., Rooseleer, J., De Fruyt, J., 2011. Measuring catatonia: a systematic review of rating scales. J. Affect. Disord. 135, 1-9.

Simpson, G.M., Angus, J.W., 1970. A rating scale for extrapyramidal side effects. Acta Psychiatr. Scand. Suppl. 212, 11-19.

Stevens, J.R., 1974. Letter: motor disorders in schizophrenia. N. Engl. J. Med. 290, 110.

Stober, G., 2001. Genetic predisposition and environmental causes in periodic and systematic catatonia. Eur. Arch. Psychiatry Clin. Neurosci. 251 (Suppl 1), I21-124.

Stober, G., Franzek, E., Beckmann, H., Schmidtke, A., 2002. Exposure to prenatal infections, genetics and the risk of systematic and periodic catatonia. J. Neural Transm. (Vienna) 109, 921-929.

Strik, W., Stegmayer, K., Walther, S., Dierks, T., 2017. Systems neuroscience of psychosis: mapping schizophrenia symptoms onto brain systems. Neuropsychobiology 75, 100-116.

Sui, J., Adali, T., Yu, Q., Chen, J., Calhoun, V.D., 2012a. A review of multivariate methods for multimodal fusion of brain imaging data. J. Neurosci. Methods 204, 68-81.

Sui, J., Yu, Q., He, H., Pearlson, G.D., Calhoun, V.D., 2012b. A selective review of multimodal fusion methods in schizophrenia. Front. Hum. Neurosci. 6, 27.

Teremetz, M., Amado, I., Bendjemaa, N., Krebs, M.O., Lindberg, P.G., Maier, M.A., 2014. Deficient grip force control in schizophrenia: behavioral and modeling evidence for altered motor inhibition and motor noise. PLoS ONE 9, e111853.

Thomann, P.A., Hirjak, D., Kubera, K.M., Stieltjes, B., Wolf, R.C., 2015. Neural network activity and neurological soft signs in healthy adults. Behav. Brain Res. 278, 514-519.

Ungvari, G.S., Carroll, B.T., 2004. Nosology. In: In: Caroff, SN, M.S., Francis A, Fricchione, GL (Eds.). In: Catatonia: from Psychopathology to Neurobiology, 2004. American Psychiatric Association Publishing, Washington, DC, USA, pp. 33-43.

Ungvari, G.S., Chiu, H.F., Chow, L.Y., Lau, B.S., Tang, W.K., 1999. Lorazepam for chronic catatonia: a randomized, double-blind, placebo-controlled cross-over study. Psychopharmacology (Berl.) 142, 393-398.

Uttinger, M., Studerus, E., Ittig, S., Heitz, U., Schultze-Lutter, F., Riecher-Rossler, A., 2018. The Frankfurt Complaint Questionnaire for self-assessment of basic symptoms in the early detection of psychosis-Factor structure, reliability, and predictive validity. Int. J. Methods Psychiatr. Res. 27, e1600.

van Harten, P.N., Walther, S., Kent, J.S., Sponheim, S.R., Mittal, V.A., 2017. The clinical and prognostic value of motor abnormalities in psychosis, and the importance of instrumental assessment. Neurosci. Biobehav. Rev. 80, 476-487.

van Strien, A.M., Keijsers, C.J., Derijks, H.J., van Marum, R.J., 2015. Rating scales to measure side effects of antipsychotic medication: a systematic review. J. Psychopharmacol. 29, 857-866.

Viher, P.V., Stegmayer, K., Kubicki, M., Karmacharya, S., Lyall, A.E., Federspiel, A., Vanbellingen, T., Bohlhalter, S., Wiest, R., Strik, W., Walther, S., 2018. The cortical signature of impaired gesturing: findings from schizophrenia. Neuroimage Clin. 17, 213-221.

Waddington, J.L., 1990. Spontaneous orofacial movements induced in rodents by very long-term neuroleptic drug administration: phenomenology, pathophysiology and putative relationship to tardive dyskinesia. Psychopharmacology (Berl.) 101, 431-447.

Waddington, J.L., 1995. Psychopathological and cognitive correlates of tardive dyskinesia in schizophrenia and other disorders treated with neuroleptic drugs.. In: Weiner, W.J., Lang, A.E. (Eds.), Behavioral Neurology of Movement Disorders. Raven Press, New York, pp. 211-229. 
Waddington, J.L., 2020. Psychosis in Parkinson's disease and parkinsonism in antipsychotic-naïve schizophrenia spectrum psychosis: Clinical, nosological and pathobiological challenges. Acta Pharmacologica Sinica, 41, pp. 464-470.

Waddington, J.L., Crow, T.J., 1988. Abnormal involuntary movements and psychosis in the preneuroleptic era and in unmedicated patients: implications for the concept of tardive dyskinesia.. In: Wolf, M, M., A. (Eds.). In: Tardive dyskinesia: Biological Mechanisms and Clinical Aspects, 1988. American Psychiatric Press, Washington, DC, pp. 51-66.

Waddington, J.L., O’Sullivan, G.J., Tomiyama, K., 2011. Regulation of orofacial movement: dopamine receptor mechanisms and mutant models. Int. Rev. Neurobiol. 97, 39-60.

Waddington, J.L., O'Tuathaigh, C.M., 2018. Modelling the neuromotor abnormalities of psychotic illness: putative mechanisms and systems dysfunction. Schizophr. Res. 200, 12-19.

Walter, W.G., Cooper, R., Aldridge, V.J., McCallum, W.C., Winter, A.L., 1964. Contingent negative variation: an electric sign of sensorimotor association and expectancy in the human brain. Nature 203, 380-384.

Walther, S., Alexaki, D., Schoretsanitis, G., Weiss, F., Vladimirova, I., Stegmayer, K., Strik, W., Schäppi, L., 2020a. Inhibitory repetitive transcranial magnetic stimulation to treat psychomotor slowing - a transdiagnostic, mechanism based randomized double-blind controlled trial. Schizophr. Bull. Open.

Walther, S., Alexaki, D., Stegmayer, K., Vanbellingen, T., Bohlhalter, S., 2019a. Conceptual disorganization impairs hand gesture performance in schizophrenia. Schizophr. Res..

Walther, S., Bernard, J.A., Mittal, V.A., Shankman, S.A., $2019 \mathrm{~b}$. The utility of an RDoC motor domain to understand psychomotor symptoms in depression. Psychol. Med. 49, 212-216.

Walther, S., Eisenhardt, S., Bohlhalter, S., Vanbellingen, T., Muri, R., Strik, W., Stegmayer, K., 2016. Gesture performance in schizophrenia predicts functional outcome after 6 months. Schizophr. Bull. 42, 1326-1333.

Walther, S., Horn, H., Razavi, N., Koschorke, P., Muller, T.J., Strik, W., 2009a. Quantitative motor activity differentiates schizophrenia subtypes. Neuropsychobiology 60, 80-86.

Walther, S., Koschorke, P., Horn, H., Strik, W., 2009b. Objectively measured motor activity in schizophrenia challenges the validity of expert ratings. Psychiatry Res. 169, 187-190.

Walther, S., Kunz, M., Muller, M., Zurcher, C., Vladimirova, I., Bachofner, H., Scherer, K.A., Nadesalingam, N., Stegmayer, K., Bohlhalter, S., Viher, P.V., 2020b. Single session transcranial magnetic stimulation ameliorates hand gesture deficits in schizophrenia. Schizophr. Bull. 46, 286-293.

Walther, S., Mittal, V.A., 2016. Why we should take a closer look at gestures. Schizophr. Bull. 42, 259-261.

Walther, S., Mittal, V.A., 2017. Motor system pathology in psychosis. Curr. Psychiatry Rep. 19, 97.

Walther, S., Ramseyer, F., Horn, H., Strik, W., Tschacher, W., 2014a. Less structured movement patterns predict severity of positive syndrome, excitement, and disorganization. Schizophr. Bull. 40, 585-591.

Walther, S., Schappi, L., Federspiel, A., Bohlhalter, S., Wiest, R., Strik, W., Stegmayer, K., 2017a. Resting-state hyperperfusion of the supplementary motor area in catatonia. Schizophr. Bull. 43, 972-981.
Walther, S., Stegmayer, K., Federspiel, A., Bohlhalter, S., Wiest, R., Viher, P.V., 2017b. Aberrant hyperconnectivity in the motor system at rest is linked to motor abnormalities in schizophrenia spectrum disorders. Schizophr. Bull. 43, 982-992.

Walther, S., Stegmayer, K., Horn, H., Rampa, L., Razavi, N., Muller, T.J., Strik, W., 2015a. The longitudinal course of gross motor activity in schizophrenia - within and between episodes. Front. Psychiatry 6, 10.

Walther, S., Stegmayer, K., Horn, H., Razavi, N., Muller, T.J., Strik, W., 2014b. Physical activity in schizophrenia is higher in the first episode than in subsequent ones. Front. Psychiatry 5, 191.

Walther, S., Stegmayer, K., Sulzbacher, J., Vanbellingen, T., Muri, R., Strik, W., Bohlhalter, S., 2015b. Nonverbal social communication and gesture control in schizophrenia. Schizophr. Bull. 41, 338-345.

Walther, S., Stegmayer, K., Wilson, J.E., Heckers, S., 2019c. Structure and neural mechanisms of catatonia. Lancet Psychiatry 6, 610-619.

Walther, S., Strik, W., 2012. Motor symptoms and schizophrenia. Neuropsychobiology 66, 77-92.

Wasserthal, J., Maier-Hein, K.H., Neher, P.F., Northoff, G., Kubera, K.M., Fritze, S., Harneit, A., Geiger, L.S., Tost, H., Wolf, R.C., Hirjak, D., 2020. Multiparametric mapping of white matter microstructure in catatonia. Neuropsychopharmacology.

Whitty, P.F., Owoeye, O., Waddington, J.L., 2009. Neurological signs and involuntary movements in schizophrenia: intrinsic to and informative on systems pathobiology. Schizophr. Bull. 35, 415-424.

Wichniak, A., Skowerska, A., Chojnacka-Wojtowicz, J., Taflinski, T., Wierzbicka, A., Jernajczyk, W., Jarema, M., 2011. Actigraphic monitoring of activity and rest in schizophrenic patients treated with olanzapine or risperidone. J. Psychiatr. Res. 45, 1381-1386.

Willems, A.E., Sommer, I.E., Tenback, D.E., Koning, J.P., van Harten, P.N., 2016. Instrumental measurements of spontaneous dyskinesia and schizotypy in subjects with auditory verbal hallucinations and healthy controls. Psychiatry Res. 244, 24-27.

Wobrock, T., Schneider-Axmann, T., Retz, W., Rosler, M., Kadovic, D., Falkai, P., Schneider, M., 2009. Motor circuit abnormalities in first-episode schizophrenia assessed with transcranial magnetic stimulation. Pharmacopsychiatry 42, 194-201.

Wolf, R.C., Rashidi, M., Fritze, S., Kubera, K.M., Northoff, G., Sambataro, F., Calhoun, V.D., Geiger, L.S., Tost, H., Hirjak, D., 2020. A neural signature of Parkinsonism in patients with schizophrenia spectrum disorders: a multimodal MRI study using parallel ICA. Schizophr. Bull..

Wolff, A.L., O’Driscoll, G.A., 1999. Motor deficits and schizophrenia: the evidence from neuroleptic-naive patients and populations at risk. J. Psychiatry Neurosci. 24, 304-314.

Woods, S.W., 2003. Chlorpromazine equivalent doses for the newer atypical antipsychotics. J. Clin. Psychiatry 64, 663-667.

Yarden, P.E., Discipio, W.J., 1971. Abnormal movements and prognosis in schizophrenia. Am. J. Psychiatry 128, 317-323.

Zandbelt, B.B., van Buuren, M., Kahn, R.S., Vink, M., 2011. Reduced proactive inhibition in schizophrenia is related to corticostriatal dysfunction and poor working memory. Biol. Psychiatry 70, 1151-1158. 